\title{
Elevated myeloid-derived suppressor cells in pancreatic, esophageal and gastric cancer are an independent prognostic factor and are associated with significant elevation of the Th2 cytokine interleukin-13
}

\author{
Rachel F. Gabitass • Nicola E. Annels • Deborah D. Stocken • \\ Hardev A. Pandha $\cdot$ Gary W. Middleton
}

Received: 17 December 2010/Accepted: 22 April 2011/Published online: 5 June 2011

(C) The Author(s) 2011. This article is published with open access at Springerlink.com

\begin{abstract}
We undertook a comprehensive analysis of circulating myeloid-derived suppressor cells (MDSCs) and $\mathrm{T}$ regulatory cells (Tregs) in pancreatic, esophageal and gastric cancer patients and investigated whether MDSCs are an independent prognostic factor for survival. We evaluated a series of plasma cytokines and in particular reevaluated the Th2 cytokine interleukin-13 (IL-13). Peripheral blood was collected from 131 cancer patients (46 pancreatic, 60 esophageal and 25 gastric) and 54 healthy controls. PBMC were harvested with subsequent flow cytometric analysis of MDSC (HLADR ${ }^{-}$Lin $1^{\text {low/- }}$ $\left.\mathrm{CD}_{3}{ }^{+} \mathrm{CD}_{11 b^{+}}\right)$and Treg $\left(\mathrm{CD} 4^{+} \mathrm{CD} 25^{+} \mathrm{CD} 127^{\text {low } /-}\right.$ FoxP $3^{+}$) percentages. Plasma IL-2, IL-4, IL-5, IL-6, IL-10, IL-12 (p70), IL-13, IL-17, G-CSF, IFN- $\gamma$, TNF- $\alpha$ and VEGF levels were analyzed by the Bio-Plex cytokine assay. Plasma arginase I levels were analyzed by ELISA. MDSCs and Tregs were statistically significantly elevated in pancreatic, esophageal and gastric cancer compared with controls, and MDSC numbers correlated with Treg levels. Increasing MDSC percentage was associated with increased risk of death, and in a multivariate analysis, MDSC level was an independent prognostic factor for
\end{abstract}

R. F. Gabitass - N. E. Annels · H. A. Pandha ·

G. W. Middleton $(\bowtie)$

Oncology Department, Postgraduate Medical School,

University of Surrey, Surrey GU2 7WG, UK

e-mail: gmiddleton@mac.com

R. F. Gabitass · H. A. Pandha - G. W. Middleton

St Luke's Cancer Centre, Royal Surrey County Hospital,

Egerton Road, Guildford, Surrey GU2 7XX, UK

D. D. Stocken

Cancer Research UK Clinical Trials Unit,

School of Cancer Sciences, University of Birmingham,

Birmingham B15 2TT, UK survival. A unit increase in MDSC percentage was associated with a $22 \%$ increased risk of death (hazard ratio $1.22,95 \%$ confidence interval 1.06-1.41). Arginase I levels were also statistically significantly elevated in upper gastrointestinal cancer patients compared with controls. There was Th2 skewing for cytokine production in all three diseases, and importantly there were significant elevations of the pivotal Th2 cytokine interleukin-13, an increase that correlated with MDSC levels.

Keywords Myeloid-derived suppressor cell · Cancer . Prognostic factor · Cytokine - Interleukin-13 - Arginase

\section{Introduction}

Many cancers are characterized by the overproduction of a range of immunosuppressive cells and cytokines. These not only inhibit the host's antitumor immune response but also thwart attempts to augment anticancer immunity through the use of cancer vaccines. The two best-characterized immunosuppressive cell subsets are $\mathrm{FoxP}^{+} \mathrm{T}$ regulatory cells (Tregs) and myeloid-derived suppressor cells (MDSCs). The characteristics of both of these cell types have been the subject of comprehensive recent reviews [1, 2]. MDSCs arise from myeloid progenitor cells that have failed to terminally differentiate into mature granulocytes and macrophages $\left(\mathrm{HLADR}^{-} \operatorname{Lin} 1^{\text {low/-}}\right)$. Granulocytic MDSCs express CD33, CD11b, IL-4R $\alpha$, and low levels of CD15 and contain high levels of arginase. Monocytic MDSCs express the same markers but have lower levels of CD15 and also express CD14; in addition to arginase, they also express inducible nitric oxide synthase (iNOS). Naturally occurring $\mathrm{CD} 4^{+}$Tregs are characterized by the expression of the IL-2 receptor $\alpha$-chain (CD25). These cells 
naturally arise in the thymus, and after differentiation, the naive $\mathrm{CD} 4{ }^{+} \mathrm{CD} 25^{+} \mathrm{CD} 45 \mathrm{RA}^{+} \mathrm{T}$ cells are exported to the periphery [3-5]. Intracellular expression of the forkhead box protein 3 transcription factor (FoxP3) and low expression of the IL-7 receptor, CD127, are further characteristics of suppressive Tregs $[1,6]$.

While there are published data on circulating Treg levels in pancreatic cancer [7], including comprehensive clinicopathological correlations, there is little published data investigating MDSCs specifically in pancreatic cancer, or indeed in esophageal and gastric cancer. Patients with metastatic pancreatic cancer were included in an early paper characterizing granulocytic MDSCs in cancer patients with diverse primary tumors [8]. In another series of over 100 patients, which included patients with pancreatic cancer, a significant increase in circulating $\mathrm{HLADR}^{-} \mathrm{Lin}^{\text {low/- }} \mathrm{CD} 3^{+} \mathrm{CD} 11 \mathrm{~b}^{+}$MDSCs was demonstrated in cancer patients relative to controls: Increasing numbers of MDSCs correlated with increasing stage of disease and patient-derived MDSCs impaired T-cell proliferation [9].

Although elevated MDSC numbers have been reported in single tumor site series, MDSC levels, their phenotype, and their functional effects may vary from cancer to cancer. We present for the first time a comprehensive clinicopathological correlation of circulating MDSCs and Tregs in pancreatic, esophageal and gastric cancer patients, together with an assessment of the functional significance of these changes by analysis of systemic arginase I levels. We demonstrate that MDSC levels are an independent prognostic factor for survival. We have evaluated the cytokine profiles in these patients with particular reference to IL-13 levels.

\section{Materials and methods}

\section{Patients}

Twenty to thirty milliliters of venous blood was collected from pancreatic and esophago-gastric cancer patients $(N=131)$ and age-/sex-matched normal healthy controls $(N=54)$. Subjects were recruited between July 2008 and April 2010. Cancer patients were recruited from oncology clinics at St Luke's Cancer Center, Surrey, UK, and all had histologically confirmed pancreatic or esophago-gastric cancer. Age- and sex-matched healthy controls were recruited from surgical minor operation clinics at the Royal Surrey County Hospital. No subject had a history of autoimmune disease or of recent steroid therapy, and no control donor had a prior history of cancer. All subjects provided written informed consent and the study was approved by the local ethics committee. Blood was drawn into li-heparin tubes (BD Biosciences, Europe), and following centrifugation, the plasma was removed and peripheral blood mononuclear cells (PBMC) were isolated using Ficoll-Hypaque gradients. Plasma samples were stored at $-80^{\circ} \mathrm{C}$, and $\mathrm{PBMC}$ were counted, frozen at $-80^{\circ} \mathrm{C}$, and stored in liquid $N_{2}$ for subsequent batch analysis.

Cancer patients were subdivided into three groups according to the site of their primary tumor: (1) pancreatic $(N=46)$, (2) esophageal, esophago-gastric junction or cardia (primary tumor arising $\leq 5 \mathrm{~cm}$ below the esophagogastric junction) $(N=60)$, and (3) non-cardia gastric cancer patients (primary tumor arising in gastric body, fundus, or antrum) $(N=25)$. The following clinicopathological characteristics were recorded: age, sex, WHO performance status (PS), histological grade, AJCC stage (2010), prior weight loss, smoking status at time of sample collection, and whether patients received subsequent systemic treatment following immune testing.

Immunophenotypic analysis of cells

PBMC were recovered and washed in $0.15 \mathrm{M}$ phosphatebuffered saline, Dulbecco's A (Oxoid, UK). Cells were aliquoted for T-cell subset, Treg and MDSC analysis. The LIVE/DEAD Cell Stain Kit (Invitrogen, UK) was used to differentiate viable and dead cells. After washing in binding buffer (BD Biosciences, Europe), the following anti-human monoclonal antibodies were used for flow cytometry: anti-CD3-FITC, anti-CD4-PE Cy7, anti-CD8PE Cy5, anti-CD25-APC Cy7, anti-CD127-PE, antiHLADR-APC Cy7, anti-Lin1(CD3,14,16, 19,20,56)-FITC, anti-CD33-PE Cy5 and anti-CD11b-PE Cy7 (BD Biosciences, Europe). For Treg intra-nuclear FoxP3 anaylsis, permeabilization and staining for FoxP3 and an isotype control was performed for each donor using the eBioscience anti-FoxP3 staining set, according to the manufacturer's instructions. Cells were washed in binding buffer and analyzed using a MACSQuant flow cytometer with MACSQuantify software (Miltenyi Biotec). For T-cell subset and Treg analysis, the acquisition and analysis gates were restricted to the live lymphocyte population, whereas for MDSC analysis, all live cells were included. $\mathrm{CD}^{+}$ $\mathrm{CD}^{+}$and $\mathrm{CD}^{+} \mathrm{CD}^{+}$cells were calculated as a percentage of live $\mathrm{CD}^{+}$lymphocytes. Tregs were identified as $\mathrm{CD} 4^{+} \mathrm{CD} 25^{+} \mathrm{CD} 127^{\text {low/ }-} \mathrm{FoxP}^{+}$and calculated as a percentage of live $\mathrm{CD} 4^{+}$lymphocytes. Finally, $\mathrm{HLADR}^{-}$ Lin $1^{\text {low/- }} \mathrm{CD} 3^{+} \mathrm{CD} 11 \mathrm{~b}^{+}$MDSCs were calculated as a percentage of total live PBMC.

\section{Arginase I ELISA}

Plasma arginase I levels in cancer patients $(N=119)$ and controls $(N=31)$ were analyzed using an enzyme-linked 
immunosorbent assay specific for human arginase I (liver type) using a commercially available kit (BioVendor, UK). Hemolyzed samples were excluded. Samples were assayed in duplicate and the mean absorbance was calculated from the standard curve.

Bio-plex cytokine assay

Plasma IL-2, IL-4, IL-5, IL-6, IL-10, IL-12 (p70), IL-13, IL-17, G-CSF, IFN- $\gamma$, TNF- $\alpha$ and VEGF levels in cancer patients $(N=119)$ and controls $(N=33)$ were analyzed using the Bio-Plex human cytokine assay (Bio-Rad, UK), using Bio-Plex software. Hemolyzed samples were excluded and samples were assayed in duplicate.

\section{Interleukin-13 ELISA}

For validation of IL-13 levels, plasma IL-13 levels in pancreatic cancer patients $(N=24)$ and controls $(N=18)$ were analyzed using an enzyme-linked immunosorbent assay specific for human IL-13 using a commercially available kit (Thermo Scientific, UK). Hemolyzed samples were excluded. Samples were assayed in duplicate and the mean absorbance was calculated from the standard curve.

\section{Statistical analysis}

Clinicopathological variables included age, diagnosis, WHO performance status, tumor grade, AJCC 2010 stage, weight loss, smoking status at time of sample collection, prior treatment status and whether patients received any systemic therapy following sample donation. Continuous variables were summarized as medians and ranges. Median levels of MDSC, Treg, arginase I and cytokines were compared in pancreatic, esophageal and gastric cancer patients versus controls using the nonparametric twosample Wilcoxon rank sum test and applying a Bonferroni correction to control for multiple testing (statistical significance adjusted to $P<0.0125$ ). The association between two continuous factors was investigated calculating the Spearman's correlation coefficient.

Independent factors significantly associated with survival were identified using log-rank (LR) analysis for categorical variables and univariate Cox proportional hazards models for continuous variables (Wald test statistic), including consideration of transformations for nonlinear relationships with hazard. MDSC level was analyzed as a continuous covariate and required no transformation. All variables significant at the $10 \%$ level on univariate analysis were considered further in the multivariate setting. Multivariate Cox proportional hazards models were derived using backward elimination variable selection based on a $10 \%$ level of significance, including subsequent systemic therapy in all models in view of its clinical relevance. Adjusted hazard ratios for each significant independent factor are presented. Plots of survival estimates are presented using the method of Kaplan and Meier.

\section{Results}

Patients

We analyzed peripheral blood mononuclear cells and cytokine profiles of 46 patients with pancreatic cancer, 60 with esophageal cancer, 25 with gastric cancer and 54 age-/ sex-matched controls. The patient characteristics are shown in Table 1.

Following blood donation, the majority of patients subsequently received systemic therapy (80.9\%). Twentyone patients in the pancreatic cohort received standard gemcitabine-based chemotherapy and 19 received gemcitabine and capecitabine chemotherapy in combination with either concomitant or sequential treatment with the anti-telomerase class II peptide vaccine, GV1001. The 7 esophageal cancer patients who went on to receive chemotherapy and a biological agent all received standard chemotherapy followed by treatment with an experimental agent upon progression. The 3 esophageal cancer patients who were subsequently treated in the context of a randomized control trial received chemotherapy in combination with an EGFR monoclonal antibody or placebo (treatment blinded). Of the minority of upper GI patients who had received treatment prior to immune testing $(32.1 \%)$, 11 had received neoadjuvant or adjuvant chemotherapy prior to relapse and 31 had received prior palliative chemotherapy. None of these patients had received therapy within 8 weeks prior to blood donation, and all had progressed at the time of immune testing.

MDSCs are elevated in pancreatic, gastric and esophageal cancer and are associated with elevations of arginase I and Tregs

MDSC percentages were statistically significantly elevated in pancreatic, esophageal and gastric cancer, when compared with controls (Fig. 1; Table 2), with median (range) percentages of $2.1(0.2-11.2): P<0.001,1.3(0.4-6.0)$ : $P<0.001,1.5(0.2-10.0): P=0.002$, and controls 0.8 $(0.1,2.0)$, respectively. There was no significant difference in MDSC percentage in the group of patients who had received any chemotherapy prior to immune testing and those who had not $(P=0.61)$. 
Table 1 Patient characteristics

\begin{tabular}{|c|c|c|c|c|c|}
\hline Variable & Category & $\begin{array}{l}\text { Pancreas } \\
N=46\end{array}$ & $\begin{array}{l}\text { Esophagus } \\
N=60\end{array}$ & $\begin{array}{l}\text { Gastric } \\
N=25\end{array}$ & $\begin{array}{l}\text { UGI cancer } \\
N=131\end{array}$ \\
\hline \multirow[t]{4}{*}{ WHO performance status } & $0 / 1$ & $28(60.9 \%)$ & $39(65.0 \%)$ & $16(64.0 \%)$ & $83(63.4 \%)$ \\
\hline & 2 & $12(26.1 \%)$ & $16(26.7 \%)$ & $6(24.0 \%)$ & $34(26.0 \%)$ \\
\hline & 3 & $5(10.9 \%)$ & $4(6.7 \%)$ & $3(12.0 \%)$ & $12(9.2 \%)$ \\
\hline & Unknown & $1(2.2 \%)$ & $1(1.7 \%)$ & $0(0.0 \%)$ & $2(1.5 \%)$ \\
\hline \multirow[t]{4}{*}{ Tumor grade } & 1 & $2(4.3 \%)$ & $1(1.7 \%)$ & $0(0.0 \%)$ & $3(2.3 \%)$ \\
\hline & 2 & $12(26.1 \%)$ & $18(30.0 \%)$ & $6(24.0 \%)$ & $36(27.5 \%)$ \\
\hline & 3 & $16(34.8 \%)$ & $40(66.7 \%)$ & $17(68.0 \%)$ & $73(55.7 \%)$ \\
\hline & Not assessable ${ }^{a}$ & $16(34.8 \%)$ & $1(1.7 \%)$ & $2(8.0 \%)$ & $19(14.5 \%)$ \\
\hline \multirow[t]{3}{*}{ AJCC stage 2010} & II/III & $11(23.9 \%)$ & $25(41.7 \%)$ & $8(32.0 \%)$ & $44(33.6 \%)$ \\
\hline & IV & $33(71.7 \%)$ & $34(56.7 \%)$ & $17(68.0 \%)$ & $84(64.1 \%)$ \\
\hline & Not assessable ${ }^{b}$ & $2(4.3 \%)$ & $1(1.7 \%)$ & $0(0.0 \%)$ & $3(2.3 \%)$ \\
\hline \multirow[t]{4}{*}{ Weight loss } & None & $17(37.0 \%)$ & $21(35.0 \%)$ & $5(20.0 \%)$ & $43(32.8 \%)$ \\
\hline & $\leq 10 \%$ & $12(26.1 \%)$ & $20(33.3 \%)$ & $4(16.0 \%)$ & $36(27.5 \%)$ \\
\hline & $>10 \%$ & $16(34.8 \%)$ & $17(28.3 \%)$ & $14(56.0 \%)$ & $47(35.9 \%)$ \\
\hline & Unknown & $1(2.2 \%)$ & $2(3.3 \%)$ & $2(8.0 \%)$ & $5(3.8 \%)$ \\
\hline \multirow[t]{5}{*}{ Smoking status } & Current & $7(15.2 \%)$ & $12(20.0 \%)$ & $5(20.0 \%)$ & $24(18.3 \%)$ \\
\hline & Ex $\leq 12$ months & $2(4.3 \%)$ & $3(5.0 \%)$ & $1(4.0 \%)$ & $6(4.6 \%)$ \\
\hline & Ex $>12$ months & $17(37.0 \%)$ & $18(30.0 \%)$ & $10(40.0 \%)$ & $45(34.4 \%)$ \\
\hline & Never & $15(32.6 \%)$ & $22(36.7 \%)$ & $6(24.0 \%)$ & $43(32.8 \%)$ \\
\hline & Unknown & $5(10.9 \%)$ & $5(8.3 \%)$ & $3(12.0 \%)$ & $13(9.9 \%)$ \\
\hline \multirow[t]{3}{*}{ Prior treatment status } & None & $32(69.6 \%)$ & $38(63.3 \%)$ & $19(76.0 \%)$ & $89(67.9 \%)$ \\
\hline & $\begin{array}{l}\text { Adjuvant/Neoadjuvant } \\
\text { chemotherapy }\end{array}$ & $3(6.5 \%)$ & $7(11.7 \%)$ & $1(4.0 \%)$ & $11(8.4 \%)$ \\
\hline & Palliative chemotherapy & $11(23.9 \%)$ & $15(25.0 \%)$ & $5(20.0 \%)$ & $31(23.7 \%)$ \\
\hline \multirow[t]{6}{*}{ Subsequent treatment status } & None & $6(13.0 \%)$ & $13(21.7 \%)$ & $6(24.0 \%)$ & $25(19.1 \%)$ \\
\hline & Chemotherapy & $21(45.7 \%)$ & $28(46.7 \%)$ & $19(76.0 \%)$ & $68(51.9 \%)$ \\
\hline & Chemoradiation & $0(0.0 \%)$ & $8(13.3 \%)$ & $0(0.0 \%)$ & $8(6.1 \%)$ \\
\hline & Biological agent & $0(0.0 \%)$ & $1(1.7 \%)$ & $0(0.0 \%)$ & $1(0.8 \%)$ \\
\hline & Chemotherapy and biological agent & $19(41.3 \%)$ & $7(11.7 \%)$ & $0(0.0 \%)$ & $26(19.8 \%)$ \\
\hline & Randomized controlled trial & $0(0.0 \%)$ & $3(5.0 \%)$ & $0(0.0 \%)$ & $3(2.3 \%)$ \\
\hline \multirow[t]{3}{*}{ Survival status } & Alive & $9(19.6 \%)$ & $23(38.3 \%)$ & $8(32.0 \%)$ & $40(30.5 \%)$ \\
\hline & Dead & $37(80.4 \%)$ & $37(61.7 \%)$ & $17(68.0 \%)$ & $91(69.5 \%)$ \\
\hline & Unknown & $0(0.0 \%)$ & $0(0.0 \%)$ & $0(0.0 \%)$ & $0(0.0 \%)$ \\
\hline
\end{tabular}

a Tumor grade not assessable due to insufficient tissue (e.g., fine-needle aspirate, cytological diagnosis)

b Stage not assessable with tumor recurrence following prior resection

Arginase I was elevated in all three diseases, and this achieved statistical significance in esophageal and gastric cancer when using a Bonferroni correction for multiple testing. There was a strong trend toward increasing arginase I level in pancreatic cancer, which did not reach statistical significance $(P=0.020)$. Treg levels were also statistically significantly elevated in all three diseases compared with controls $(P \leq 0.002)$, and there was a positive correlation between MDSC and Treg percentages with a Spearman's rank correlation of 0.43 . There was no correlation between MDSC and CD4 or CD8 percentages (data not shown). The majority of patients in the study had stage IV disease (64.1\%) and grade 3 tumors (55.7\%). As only 44 patients $(33.6 \%)$ had stage II-III disease, such patients were combined for analysis. In our dataset, there was no evidence of increasing MDSC percentage or of arginase I concentration with stage $(P=0.51$ and $P=0.53$, respectively). However, there was a tendency for patients harboring high-grade tumors to have higher arginase levels compared with grade $1 / 2$ tumors $(P=0.044)$. There was no significant effect of grade on MDSC\% $(P=0.61)$. 
Cytokine profiling of pancreatic, esophageal and gastric cancer shows Th2 skewing and significant elevations of the Th2 cytokine IL-13 (Table 3)

Table 3 shows cytokine levels for IL-2, IL-4, IL-5, IL-6, IL-10, IL-12, IL-13, IL-17, G-CSF, IFN- $\gamma$, TNF- $\alpha$ and VEGF. IL-5, IL-6 and IL10 levels were all statistically significantly elevated in patients' plasma, compared with controls $(P \leq 0.004)$. We analyzed IL-13 levels by BioPlex assay for all three cancers and demonstrated statistically significant increases in IL-13 in all three diseases compared with controls $(P<0.001)$. We confirmed the elevated IL-13 levels in pancreatic cancer patients versus controls using a separate ELISA (Thermo Scientific, UK) and confirmed a statistically significant increase in IL-13 $(P<0.001)$. As expected, there was also a highly statistically significant elevation of VEGF in cancer patients. There was a positive correlation between MDSC levels and IL-13 with a Spearman's rank correlation of 0.32 .

MDSC levels are an independent prognostic factor in pancreatic, esophageal and gastric cancer (Tables 4, 5, 6, Fig. 2)

Ninety-one (69\%) of the 131 cancer patients had died at the time of analysis. Median follow-up of the 40 alive patients was 8.3 months (inter-quartile range: 4.1-13.5), similar across diagnostic groups. Tables 4 and 5 show the univariate analysis of survival. As was expected, performance status $\left(\chi_{\text {Log-Rank }}^{2}=28.7, P<0.001\right)$, AJCC stage $\left(\chi_{\text {Log-Rank }}^{2}=\right.$ 6.9, $P=0.008)$, and weight loss $\left(\chi_{\text {Log-Rank }}^{2}=7.7\right.$, $P=0.022)$ were statistically significantly associated with outcome. Median survival for patients with pancreatic cancer (5.0 months, 95\% CI: 3.4, 7.3) was worse than that for gastric (5.9 months, 95\% CI: 4.0, 10.6) and esophageal cancer $(9.3$ months, $95 \%$ CI: 7.2, 12.6). MDSC level was significantly associated with survival $\left(\chi_{\text {Wald }}^{2}=21.3\right.$, $P<0.001$ ), Table 5. Treg percentage, however, was not. There was no evidence that tumor grade, smoking status, prior or subsequent treatment status had an impact on survival in this dataset.

No control sample had an MDSC percentage of greater than $2.0 \%$ of their total live PBMC $(N=47)$. Patients were dichotomized into those with above normal range of MDSC percentage (MDSCs $>2.0 \%$ ) and those with an MDSC level in the normal range (MDSCs $\leq 2.0 \%$ ). Fortythree patients with elevated MDSCs had an inferior survival, with a median survival of 4.6 months (95\% CI: 2.2 , 6.0) and 12-month survival of $10.4 \%$ compared with 80 patients with normal MDSCs, median survival of 9.3 months $(95 \%$ CI: $6.3,12.1)$ and 12 -month survival of $39 \%$ (Fig. 2a).
A multivariable model for overall survival was based on 115 patients (82 deaths), considering all variables significant in the univariate analysis with $P<0.1$. The final model included subsequent chemotherapy and selected diagnostic group $\left(\chi_{\text {Wald }}^{2}=6.7, P=0.036\right)$, AJCC stage $\left(\chi_{\text {Wald }}^{2}=3.3\right.$, $P=0.071)$, performance status $\left(\chi_{\text {Wald }}^{2}=16.2, P<0.001\right)$, and MDSC percentage $\left(\chi_{\text {Wald }}^{2}=7.3, P=0.007\right)$ as significant prognostic factors of survival (Table 6). Although weight loss was significant in the univariate analysis, it was not significant in the multivariate setting and therefore was not included in the final analysis. MDSC level retained statistical significance in the multivariable model when adjusted by the effects of other prognostic factors. A unit increase in MDSC percentage was associated with a $22 \%$ increased risk of death (hazard ratio of 1.22 (95\% CI: 1.06-1.41), Fig. 2b.

\section{Discussion}

The efficacy of cancer vaccines and other immunotherapies will be improved by addressing the immunosuppressive factors associated with malignancy, both systemically and in the local tumor microenvironment. In this comprehensive analysis of some of these factors, we have shown a statistically significant increase in circulating MDSC numbers in patients with pancreatic, esophageal and gastric cancer compared with age- and sex-matched controls. MDSCs exert their immunosuppressive activity through multiple mechanisms, one of these being through arginine depletion. MDSCs express high levels of arginase: Arginase hydrolyzes the amino acid L-arginine to ornithine and urea. There are two isoforms of arginase, cytoplasmic arginase I and mitochondrial arginase II, encoded by two different genes. MDSC expressing arginase I deplete L-arginine from the microenvironment and profoundly inhibit T-cell function [10, 11]. Inhibition of arginase I restores T-cell function in vitro and induces an antitumor response in vivo [11]. Previously, increased numbers of MDSCs in the peripheral blood of renal cancer patients correlated with low L-arginine and high ornithine levels in plasma, and a profound T-cell dysfunction [12]. In this study, we have demonstrated elevations of plasma arginase I compared with controls in all three cancer types, and this difference achieved levels of statistical significance in esophageal and gastric cancer.

MDSCs may exert their immunosuppressive effects partially through the induction of Tregs as reported in hepatocellular carcinoma [13]. Sunitinib caused a significant reduction in MDSC numbers in patients with renal cell carcinoma and the change in $\mathrm{T}$ regulatory cells tracked those of MDSC numbers with a significant correlation 

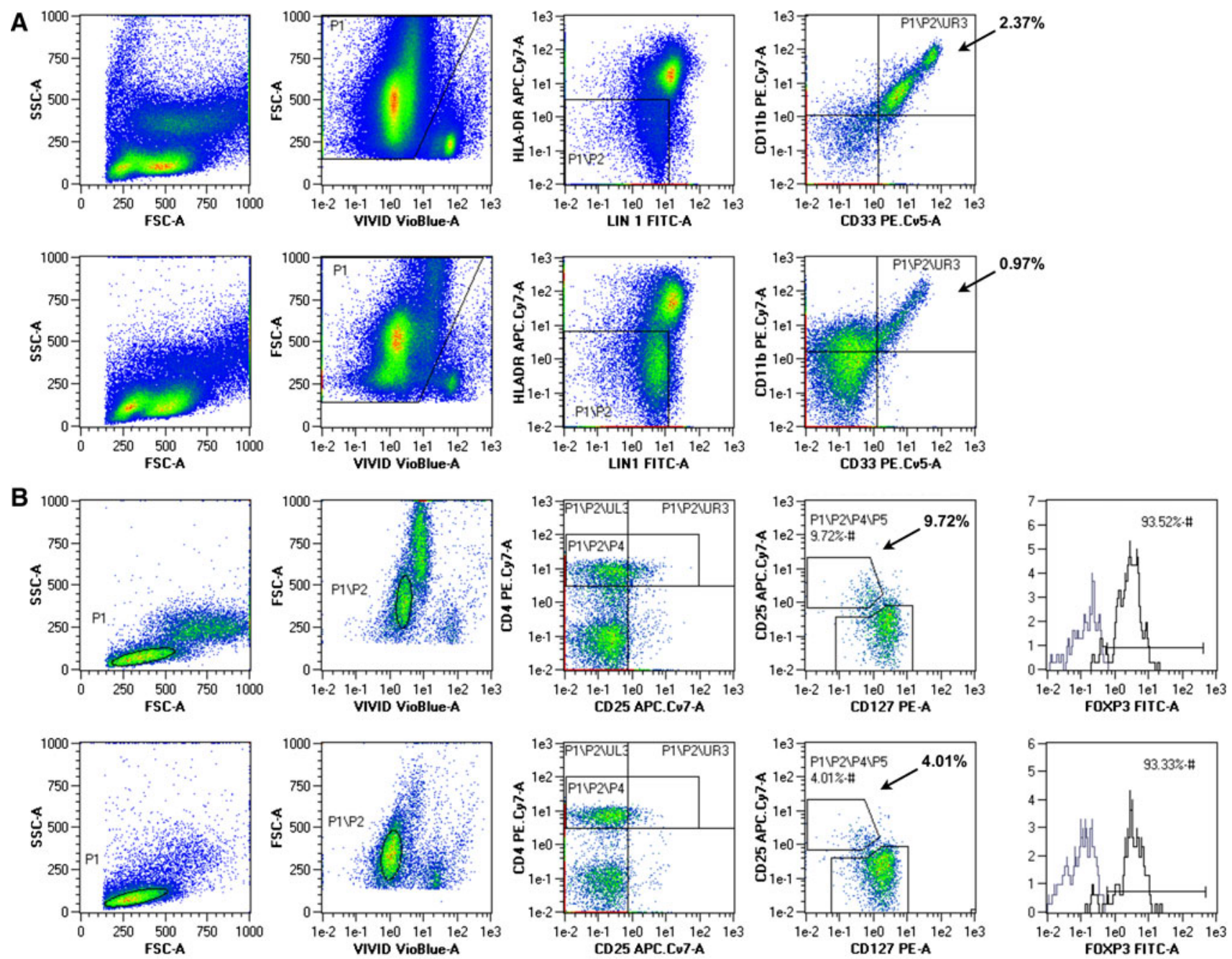

C

\%MDSC HLADR-LIN1 ${ }^{\text {lowl- }}{\text { CD } 33^{+} \text {CD11b }}^{+}$



D

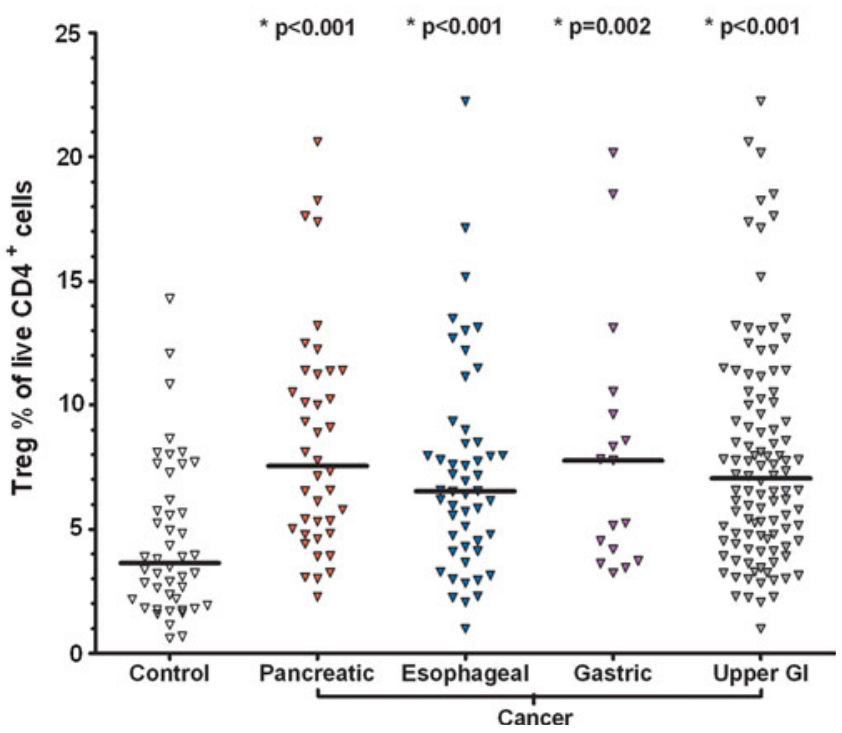


4 Fig. 1 MDSC and Treg FACS and scatter plots of cancer patients and healthy controls. a live $\mathrm{HLADR}^{-} \mathrm{Lin} 1^{\text {low/-}} \mathrm{CD}^{+} 3^{+} \mathrm{CD} 11 \mathrm{~b}^{+}$ MDSC FACS gating of PBMC of a pancreatic cancer patient (above) and a healthy control (below). P1, the ViViD low population represents viable cells with reduced amine staining, P2 represents the HLADR negative, lineage low/negative population and UR3, live $\mathrm{HLADR}^{-}$Lin $1^{\text {low/ }-} \mathrm{CD} 33^{+} \mathrm{CD} 11 \mathrm{~b}^{+}$cells, calculated as a percentage of live cells in $\mathrm{P} 1$. b live $\mathrm{CD} 4^{+} \mathrm{CD} 25^{+} \mathrm{CD} 127^{\text {low } /-}$ FoxP $^{+}$Treg FACS gating of PBMC of the same pancreatic cancer patient (above) and healthy control (below). P1, the lymphocyte population. P2, viable lymphocytes. $\mathrm{P} 4, \mathrm{CD} 4^{+}$population. $\mathrm{P} 5, \mathrm{CD} 25^{+} \mathrm{CD} 127^{\text {low/- }}$. Histograms represent the $\mathrm{FoxP}^{+}$Treg population $\left(\mathrm{FITC}^{+}\right.$, right) and the FoxP3 ${ }^{-}$non-Treg population. Tregs are calculated as a percentage of live $\mathrm{CD}^{+}{ }^{+}$lymphocytes. $\mathbf{c}$ scatter plot of MDSC $\%$ in controls and cancer patients. Bar denotes median in each group. *, statistically significant difference from healthy controls. d scatter plot of Treg \% in controls and cancer patients

between the two [14]. We found a significant increase in Tregs in pancreatic, esophageal and gastric cancer compared with controls and a positive correlation between MDSC and Treg percentage with a Spearman's correlation of 0.43 . These data complement previously published data on FoxP3 ${ }^{+}$Tregs in pancreatic cancer, in which a direct correlation between high levels of Tregs within the tumoral lymphocytic infiltrate and the presence of distant metastasis and high tumor stage and grade was demonstrated [7]. In a multivariate model adjusting for other clinical and pathological variables, they found that the prevalence of Tregs in the $\mathrm{CD}^{+}$T-cell population was an independent prognostic factor. The study did not directly ascertain circulating Treg numbers in the blood of these patients.

A unique and important finding of our study is that MDSC numbers are an independent prognostic factor in patients with pancreatic and esophago-gastric cancer. We constructed a multivariable model in 115 patients for overall survival including key variables of diagnosis, performance status, stage and the use of systemic therapy following immune assessment. MDSCs remained an independent prognostic factor significantly related to survival, with a unit increase in MDSCs being associated with a $22 \%$ increased risk of death (hazard ratio of $1.22,95 \% \mathrm{CI}$ 1.06-1.41). Should these findings be independently validated, MDSC percentage could become a parameter for routine use in the prognostic modeling of these diseases. Although we have not shown an association with MDSC and stage (as was demonstrated in the work of DiazMontero and colleagues [9]), our study specifically reports on only 3 tumor sites. Their work included 17 different cancers, nearly half of which were breast cancer patients. It may be that some cancers are associated with profound immunosuppression even at an early stage while other cancers may only generate severe systemic immunosuppression when metastatic. This underlies the importance of reporting immune status data separately for each primary cancer type.

Bellone and colleagues first reported an increase in IL-10 and TGF- $\beta$ concentrations in the sera of pancreatic cancer patients and showed that the anti-proliferative activity of pancreatic carcinoma-conditioned medium on PBMCs was accounted for mainly by the combined action of IL-10 and TGF- $\beta$ [15]. There was an increase in IL-4 production and decrease in interferon- $\gamma$ and IL-12 production from stimulated PBMCs, thus demonstrating a skewing of T-cell cytokine production toward a Th2 immunophenotype. We confirm this Th2 skewing in pancreatic cancer and extend these observations to esophageal and gastric cancer, demonstrating statistically significant increases in the plasma concentrations of the Th2 cytokines IL-5, IL-6 and IL-10 in these patients compared with controls. The elevation of IL-6 is intriguing in view of

Table 2 MDSC, Treg and arginase I levels

\begin{tabular}{|c|c|c|c|c|c|}
\hline $\begin{array}{l}\text { Number patients } \\
\text { median (range) } P \text { value }\end{array}$ & $\begin{array}{l}\text { Control } \\
N=54\end{array}$ & $\begin{array}{l}\text { Pancreas } \\
N=46\end{array}$ & $\begin{array}{l}\text { Esophagus } \\
N=60\end{array}$ & $\begin{array}{l}\text { Gastric } \\
N=25\end{array}$ & $\begin{array}{l}\text { UGI cancer } \\
N=125\end{array}$ \\
\hline $\operatorname{MDSC}(\%)$ & $\begin{array}{l}N=47 \\
0.8(0.1,2.0)\end{array}$ & $\begin{array}{l}N=44 \\
2.1(0.2,11.2) \\
P<0.001\end{array}$ & $\begin{array}{l}N=56 \\
1.3(0.4,6.0) \\
P<0.001\end{array}$ & $\begin{array}{l}N=23 \\
1.5(0.2,10.0) \\
P=0.002\end{array}$ & $\begin{array}{l}N=123 \\
1.4(0.2,11.2) \\
P<0.001\end{array}$ \\
\hline Treg $(\%)$ & $\begin{array}{l}N=46 \\
3.6(0.6,14.3)\end{array}$ & $\begin{array}{l}N=40 \\
7.5(2.3,20.6) \\
P<0.001\end{array}$ & $\begin{array}{l}N=51 \\
6.5(1.0,22.2) \\
P<0.001\end{array}$ & $\begin{array}{l}N=17 \\
7.8(3.2,20.2) \\
P=0.002\end{array}$ & $\begin{array}{l}N=108 \\
7.0(1.0,22.2) \\
P<0.001\end{array}$ \\
\hline Arginase I conc. (ng/ml) & $\begin{array}{l}N=31 \\
7.7(5.0,97.4)\end{array}$ & $\begin{array}{l}N=44 \\
16.7(5.1,293.0) \\
P=0.020(\mathrm{~ns})\end{array}$ & $\begin{array}{l}N=53 \\
19.9(5.1,167.8) \\
P<0.001\end{array}$ & $\begin{array}{l}N=22 \\
36.5(9.2,195.0) \\
P<0.001\end{array}$ & $\begin{array}{l}N=119 \\
22.0(5.1,293.0) \\
P<0.001\end{array}$ \\
\hline
\end{tabular}

Number of patients $(N)$, median (range), Wilcoxon rank sum test $P$ value of cancer group versus control. The UGI (upper gastrointestinal) cancer group consists of the pancreatic, esophageal and gastric cancer patients combined. Bonferonni correction applied due to multiple testing with the control arm, statistical significance adjusted to $P<0.0125$ 
Table 3 Bio-plex assay of plasma cytokines in controls and cancer patients

\begin{tabular}{|c|c|c|c|c|c|}
\hline $\begin{array}{l}\text { Number patients } \\
\text { median (range) } P \text { value }\end{array}$ & Control $N=33$ & Pancreas $N=43$ & Esophagus $N=52$ & Gastric $N=24$ & UGI cancer $N=119$ \\
\hline IL-2 & $\begin{array}{l}21.1 \\
(0,4434.9)\end{array}$ & $\begin{array}{l}90.7 \\
(0,6254.2) \\
P=0.38\end{array}$ & $\begin{array}{l}70.6 \\
(0,6085.6) \\
P=0.16\end{array}$ & $\begin{array}{l}82.6 \\
(0,2543.0) \\
P=0.26\end{array}$ & $\begin{array}{l}81.6 \\
(0,6254.2) \\
P=0.17\end{array}$ \\
\hline IL-4 & $\begin{array}{l}1.2 \\
(0,47.4)\end{array}$ & $\begin{array}{l}0 \\
(0,190.5) \\
P=0.87\end{array}$ & $\begin{array}{l}0 \\
(0,32.8) \\
P=0.020(\mathrm{~ns})\end{array}$ & $\begin{array}{l}8.7 \\
(0,123.2) \\
P=0.0061\end{array}$ & $\begin{array}{l}0 \\
(0,190.5) \\
P=0.84\end{array}$ \\
\hline IL-5 & $\begin{array}{l}0 \\
(0,117.0)\end{array}$ & $\begin{array}{l}7.4 \\
(0,883.2) \\
P=0.004\end{array}$ & $\begin{array}{l}10.6 \\
(0,96.8) \\
P<0.001\end{array}$ & $\begin{array}{l}10.2 \\
(2.7,242.2) \\
P<0.001\end{array}$ & $\begin{array}{l}9.6 \\
(0,883.2) \\
P<0.001\end{array}$ \\
\hline IL-6 & $\begin{array}{l}86.3 \\
(8.6,2038.3)\end{array}$ & $\begin{array}{l}211.3 \\
(30.7,9352.1) \\
P<0.001\end{array}$ & $\begin{array}{l}184.1 \\
(24.7,4606.9) \\
P<0.001\end{array}$ & $\begin{array}{l}234.0 \\
(13.5,3009.3) \\
P=0.0029\end{array}$ & $\begin{array}{l}197.6 \\
(13.5,9352.1) \\
P<0.001\end{array}$ \\
\hline IL-10 & $\begin{array}{l}16.8 \\
(0,214.5)\end{array}$ & $\begin{array}{l}39.7 \\
(0.3,918.7) \\
P<0.001\end{array}$ & $\begin{array}{l}38.0 \\
(0,668.7) \\
P<0.001\end{array}$ & $\begin{array}{l}63.8 \\
(5.7,433.0) \\
P<0.001\end{array}$ & $\begin{array}{l}42.9 \\
(0.3,918.7) \\
P<0.001\end{array}$ \\
\hline IL-12 (p70) & $\begin{array}{l}135.4 \\
(0,651.4)\end{array}$ & $\begin{array}{l}149.9 \\
(0,12714.9) \\
P=0.41\end{array}$ & $\begin{array}{l}208.5 \\
(0,9696.6) \\
P=0.074\end{array}$ & $\begin{array}{l}363.3 \\
(0,6967.5) \\
P=0.0026\end{array}$ & $\begin{array}{l}201.6 \\
(0,12714.9) \\
P=0.038(\mathrm{~ns})\end{array}$ \\
\hline IL-13 & $\begin{array}{l}27.5 \\
(0,148.5)\end{array}$ & $\begin{array}{l}112.6 \\
(0,2140.0) \\
P<0.001\end{array}$ & $\begin{array}{l}74.9 \\
(7.6,742.6) \\
P<0.001\end{array}$ & $\begin{array}{l}84.4 \\
(7.6,715.2) \\
P<0.001\end{array}$ & $\begin{array}{l}87.0 \\
(0,2140.0) \\
P<0.001\end{array}$ \\
\hline IL-17 & $\begin{array}{l}0 \\
(0,341.8)\end{array}$ & $\begin{array}{l}0 \\
(0,143.8) \\
P=0.31\end{array}$ & $\begin{array}{l}0 \\
(0,427.3) \\
P=0.56\end{array}$ & $\begin{array}{l}0 \\
(0,460.5) \\
P=0.37\end{array}$ & $\begin{array}{l}0 \\
(0,460.5) \\
P=0.36\end{array}$ \\
\hline GCSF & $\begin{array}{l}51.6 \\
(0,235.9)\end{array}$ & $\begin{array}{l}52.6 \\
(0,328.9) \\
P=0.92\end{array}$ & $\begin{array}{l}19.8 \\
(0,249.9) \\
P=0.021(\mathrm{~ns})\end{array}$ & $\begin{array}{l}53.6 \\
(2.6,153.0) \\
P=0.58\end{array}$ & $\begin{array}{l}39.7 \\
(0,328.9) \\
P=0.35\end{array}$ \\
\hline IFN- $\gamma^{\mathrm{a}}$ & $\begin{array}{l}876.7 \\
(0,25060.4)\end{array}$ & $\begin{array}{l}192.6 \\
(0,10926923.8) \\
P=0.11\end{array}$ & $\begin{array}{l}890.8 \\
(0,26288.0) \\
P=0.51\end{array}$ & $\begin{array}{l}1311.6 \\
(0,128613.3) \\
P=0.25\end{array}$ & $\begin{array}{l}725.8 \\
(0,10926923.8) \\
P=0.48\end{array}$ \\
\hline $\mathrm{TNF}-\alpha^{\mathrm{a}}$ & $\begin{array}{l}29.0 \\
(0,1422.5)\end{array}$ & $\begin{array}{l}36.7 \\
(0,16113.4) \\
P=0.67\end{array}$ & $\begin{array}{l}0 \\
(0,2167.3) \\
P=0.046(\mathrm{~ns})\end{array}$ & $\begin{array}{l}50.9 \\
(0,3730.7) \\
P=0.33\end{array}$ & $\begin{array}{l}27.3 \\
(0,16113.4) \\
P=0.61\end{array}$ \\
\hline VEGF $^{a}$ & $\begin{array}{l}798.5 \\
(214.7,4378.3)\end{array}$ & $\begin{array}{l}1232.1 \\
(0,6957.3) \\
P=0.068\end{array}$ & $\begin{array}{l}2120.2 \\
(160.8,14459.6) \\
P<0.001\end{array}$ & $\begin{array}{l}2322.7 \\
(315.7,11915.6) \\
P<0.001\end{array}$ & $\begin{array}{l}1711.1 \\
(0,14459.6) \\
P<0.001\end{array}$ \\
\hline
\end{tabular}

Number of patients $(N)$, median, (Range), Wilcoxon rank sum test $P$ value of cancer group versus control. The UGI (upper gastrointestinal) cancer group consists of the pancreatic, esophageal and gastric cancer patients combined. Bonferonni correction applied due to multiple testing with the control arm, statistical significance adjusted to $P<0.0125$

${ }^{a}$ Logarithmic transformations applied

recent data showing that the combination of IL-6 and GMCSF was the most potent generator of MDSC-like suppressor cells from normal donor PBMCs, compared with all other combinations tested [16]. This adds to other reports of IL-6 as a significant inducer of MDSCs [17].
A particularly important finding of our study is that in patients with pancreatic, esophageal and gastric cancer, there is a significant elevation of plasma IL-13. This was initially demonstrated using the Bio-Plex assay. Other groups have demonstrated significant elevations of IL-13 in 
Table 4 Univariate survival-categorical measurements

\begin{tabular}{|c|c|c|c|c|c|c|}
\hline & $N$ & Deaths & Median S(t) $(95 \% \mathrm{CI})$ & $6-\mathrm{mo} S(\mathrm{t})(\%)$ & $12-\mathrm{m} \mathrm{S}(\mathrm{t})(\%)$ & Log-rank, $P$ value \\
\hline Overall & 131 & 91 & $6.9(5.3,9.1)$ & 53.4 & 28.0 & - \\
\hline \multicolumn{7}{|l|}{ Diagnosis } \\
\hline Pancreas & 46 & 37 & $5.0(3.4,7.3)$ & 41.1 & 14.9 & \multirow[t]{3}{*}{$10.2, P=0.006$} \\
\hline Esophagus & 60 & 37 & $9.3(7.2,12.6)$ & 65.6 & 39.8 & \\
\hline Gastric & 25 & 17 & $5.9(4.0,10.6)$ & 46.9 & 25.0 & \\
\hline \multicolumn{7}{|c|}{ WHO performance status } \\
\hline $0 / 1$ & 83 & 51 & $9.1(6.9,10.7)$ & 64.6 & 34.2 & \multirow[t]{3}{*}{$28.7, P<0.001$} \\
\hline 2 & 34 & 28 & $5.1(3.9,8.5)$ & 41.3 & 20.6 & \\
\hline 3 & 12 & 11 & $2.4(1.0,4.8)$ & 11.1 & 0 & \\
\hline \multicolumn{7}{|l|}{ Tumor grade } \\
\hline $1 / 2$ & 39 & 25 & $6.9(5.4,12.1)$ & 58.6 & 36.9 & \multirow[t]{2}{*}{$0.54, P=0.46$} \\
\hline 3 & 73 & 54 & $7.2(4.8,9.2)$ & 52.8 & 26.7 & \\
\hline \multicolumn{7}{|c|}{ AJCC stage 2010} \\
\hline II/III & 44 & 25 & $10.1(6.3,12.6)$ & 65.0 & 40.6 & \multirow[t]{2}{*}{$6.9, P=0.008$} \\
\hline IV & 84 & 64 & $5.4(4.2,7.3)$ & 46.6 & 21.7 & \\
\hline \multicolumn{7}{|l|}{ Weight loss } \\
\hline None & 43 & 26 & $9.4(6.9,12.3)$ & 67.8 & 41.1 & \multirow[t]{3}{*}{$7.7, P=0.022$} \\
\hline$\leq 10 \%$ & 36 & 28 & $8.5(5.3,10.2)$ & 61.2 & 25.9 & \\
\hline$>10 \%$ & 47 & 34 & $4.8(3.7,6.9)$ & 36.3 & 19.2 & \\
\hline \multicolumn{7}{|c|}{ Smoking status } \\
\hline Current & 24 & 17 & $5.7(2.7,9.3)$ & 49.4 & 26.3 & \multirow[t]{3}{*}{$0.75, P=0.69$} \\
\hline Ex-smoker & 51 & 35 & $8.1(5.1,11.2)$ & 60.1 & 32.1 & \\
\hline Never & 43 & 30 & $7.2(5.1,10.1)$ & 55.6 & 25.1 & \\
\hline \multicolumn{7}{|c|}{ Prior treatment } \\
\hline No & 89 & 59 & $6.9(5.1,9.2)$ & 55.3 & 27.1 & \multirow[t]{2}{*}{$0.2, P=0.68$} \\
\hline Yes & 42 & 32 & $5.4(3.6,9.4)$ & 49.3 & 29.0 & \\
\hline \multicolumn{7}{|c|}{ Subsequent treatment } \\
\hline No & 25 & 20 & $5.4(2.2,10.1)$ & 45.9 & 21.0 & \multirow[t]{2}{*}{$1.3, P=0.25$} \\
\hline Yes & 106 & 71 & $7.2(5.4,9.1)$ & 55.0 & 29.6 & \\
\hline \multicolumn{7}{|l|}{ MDSC } \\
\hline$\leq 2.0 \%$ & 80 & 48 & $9.3(6.3,12.1)$ & 63.2 & 39.0 & \multirow[t]{2}{*}{$16.1, P<0.001$} \\
\hline$>2.0 \%$ & 43 & 38 & $4.6(2.2,6.0)$ & 36.6 & 10.4 & \\
\hline
\end{tabular}

$S(t)$ survival

other solid tumors, for example, melanoma, using the multiplex Luminex assay [18]. Our data contrast with that of another more recent study by Bellone and colleagues, who examined a large series of cytokines in patients with pancreatic cancer [19]. They again detected elevated levels of IL-10 and TGF- $\beta$ but found that IL-13 levels were lower in patients than in controls. We could not re-run the IL-13 assay used in their study (Euroclone ELISA) as it is no longer commercially available, but instead used a separate ELISA assay (Thermo Scientific) to validate our results in the pancreatic cohort and confirmed a significant elevation of serum IL-13 in patients relative to controls. Our data are not the first to contradict some of the IL-13 findings in the Bellone study. Formentini and colleagues demonstrated the presence of messenger RNA transcript for IL-13 in 6/6 pancreatic cancer cell lines [20]. There was detectable IL-13 protein in the conditioned media of all of these cell lines by ELISA. The IL-13 concentration in the MiaPaCa2 media was $>300 \mathrm{pg} / \mathrm{ml}$. In contrast, Bellone demonstrated minimal IL-13 expression and critically a complete absence of IL-13 in the supernatants of pancreatic cancer cell lines using the same ELISA used to assay serum in their study. This included cell lines also tested by Formentini.

An elevation of IL-13 in pancreatic cancer is a biologically plausible finding. Formentini's study demonstrated an absence of IL-13 in normal pancreatic cells but found high IL-13 in ductal cancer cells and evidence of IL-4R 

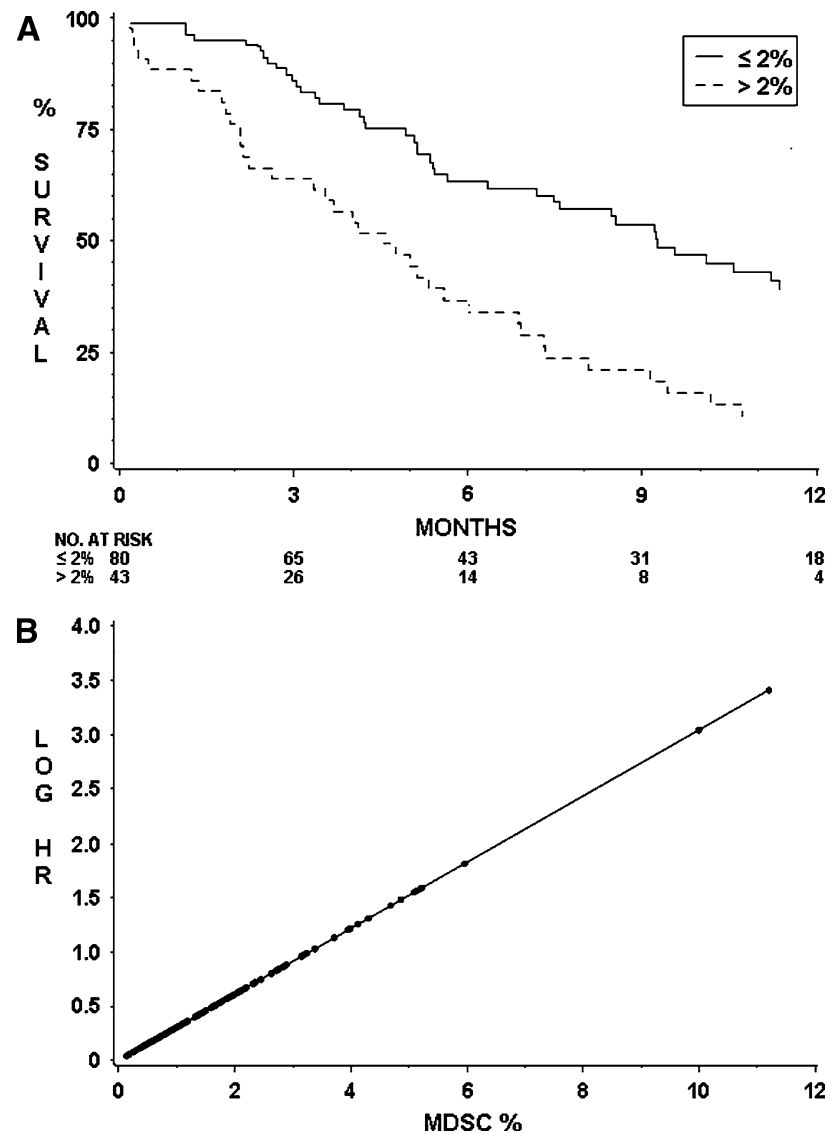

Fig. 2 a Overall survival for MDSC \% above and within normal limits. There was a significant difference between cancer patients' survival in those with a normal MDSC\% (as defined by the range seen in healthy controls, $\leq 2.00 \%$ ) and those with an elevated MDSC $\%$ $(>2.00 \%):\left(\chi_{\text {Log-Rank }}^{2}=16.1, P<0.001\right)$. b Log (hazard) plot with increasing MDSC \%. A unit increase in MDSC percentage was associated with an increased risk of death (hazard ratio $=1.22,95 \%$ CI: $1.06,1.41)$

Table 5 Univariate survival-continuous measurements

\begin{tabular}{lllcc}
\hline Variable & $N$ & Transformation $^{\mathrm{a}}$ & Wald $\chi^{2}$ & $P$ value \\
\hline Age & 131 & NA & 0.04 & 0.84 \\
Treg (\%) & 108 & NA & 1.5 & 0.22 \\
Arginase 1 & 119 & NA & 1.9 & 0.17 \\
MDSC (\%) & 123 & Linear & 21.3 & $<0.001$ \\
\hline
\end{tabular}

NA not applicable

${ }^{\text {a }}$ Nonlinear transformations considered

immunoreactivity in 40 and $43 \%$ of pancreatic cancers, respectively, (IL-13 binds a complex of the IL-13 receptor $\alpha 1$ chain (IL-13R $\alpha 1$ ) and the IL- 4 receptor $\alpha$ chain (IL$4 \mathrm{R} \alpha)$ ). High IL-13 was associated with lymph node involvement and outcome, with no patient with high expression surviving more than three years following curative resection. They presented evidence demonstrating that IL-13 is an autocrine growth factor in the disease. In some pancreatic cancer cell lines, IL-13 caused a dosedependent increase in growth, mediated by p44/42 MAPK signaling, which could be inhibited in a dose-dependent manner by IL-13-neutralizing antibodies.

The finding of a positive correlation between IL-13 levels and MDSC numbers in our study lends yet more biological plausibility to the demonstration and importance of elevated IL-13 in these diseases, given that IL-13 also appears to be pivotal for the full immunosuppressive functionality of MDSCs. Tumor-induced CD11 $\mathrm{b}^{+}$splenocytes can be sorted by the presence of the IL-4R $\alpha$ [21]. The IL-4R $\alpha$-positive cells are monocytoid, produce significant amounts of IL-13 and IFN- $\gamma$, and are suppressive. The receptor negative cells, which are polymorphonuclear-like, do not constitutively secrete these cytokines and are nonsuppressive. The presence of the receptor is essential for suppressor function: IL- $4 \mathrm{R} \alpha$ is not subserving IL-4-mediated signaling as $\mathrm{CD}_{11} \mathrm{~b}^{+}$cells from IL-4 knockout mice still suppress T-cell function. Full functionality of tumorconditioned murine MDSCs requires the coordinated effect of both IL-13 and IFN $\alpha$, released by the cells in an autocrine fashion, and results in the dual expression of arginase and nitric oxide synthase II. In cancer patients, there is a significant correlation between percentage IL4R $\alpha^{+} \mathrm{CD} 14^{+}$ cells and suppressive activity [22].

Highfill and colleagues have shown that MDSCs cultured in IL-13 are significantly more suppressive in an allogeneic mixed leukocyte reaction than MDSCs cultured without IL-13 [23]. This suppressive effect is directly mediated via arginase-mediated T-cell arginine starvation. Compared with bone marrow controls, arginase expression was 20-fold higher in MDSCs but 350-fold higher in MDSCs cultured in IL-13. Recent data have shown increased arginase activity in the plasma of patients with renal cell cancer [24]. Demonstration that this was being released from $\mathrm{CD}_{14}{ }^{-} \mathrm{CD}_{11 b^{+}}$or $\mathrm{CD} 6 \mathrm{~b}^{+}$MDSCs came from the finding of lower arginase protein activity and expression in patient MDSCs compared with autologous polymorphonuclear cells or control granulocytes, but higher arginase I mRNA expression in patient MDSCs. Furthermore, there was evidence of degranulation of arginase storage granules.

In conclusion, we have demonstrated a significant increase in circulating MDSC levels in pancreatic, esophageal and gastric cancer patients, which is correlated with elevated Treg numbers and associated with an increased expression of arginase I. Importantly, we developed a multivariable model, which has demonstrated that MDSC percentages are a strong independent prognostic factor in these tumor types. We have confirmed the Th2 cytokine skewing previously reported in pancreatic cancer and have extended these observations to esophageal and gastric cancer. Critically, we have also demonstrated significant 
Table 6 Backward elimination multivariable model for overall survival

\begin{tabular}{lllll}
\hline Variable & Levels & Wald $\chi^{2}$ & $P$ value & HR $(95 \%$ CI $)$ \\
\hline Diagnosis & Esophagus & 6.7 & 0.036 & 1.0 \\
& Gastric & & & $1.84(0.96,3.52)$ \\
& Pancreas & & & $1.84(1.11,3.05)$ \\
WHO performance status & 0,1 & 16.2 & $<0.001$ & 1.0 \\
& 2 & & & $2.09(1.26,3.47)$ \\
AJCC stage 2010 & 3 & & & $3.95(1.85,8.44)$ \\
& II, III & 3.3 & 0.071 & 1.0 \\
Subsequent treatment & IV & & & $1.60(0.96,2.68)$ \\
& No & 0.01 & 0.93 & 1.0 \\
MDSC & Yes & & & $0.97(0.56,1.70)$ \\
\hline
\end{tabular}

elevations of the important Th2 cytokine IL-13. These data not only add to our understanding of the immunobiology of these diseases but also may be of importance in informing studies incorporating MDSC inhibition strategies [25] and IL-13-directed therapies [26].

Acknowledgments BRIGHT, Better Research Into Gastro-intestinal cancer Health and Treatment, registered charity number 1064857, funded this study. St Luke's Cancer Centre's department of gastrointestinal research and Dr Sebastian Cummins contributed to the recruitment of patients.

Open Access This article is distributed under the terms of the Creative Commons Attribution Noncommercial License which permits any noncommercial use, distribution, and reproduction in any medium, provided the original author(s) and source are credited.

\section{References}

1. Qin FX (2009) Dynamic behavior and function of Foxp3+ regulatory $\mathrm{T}$ cells in tumor bearing host. Cell Mol Immunol 6:3-13 (review)

2. Ostrand-Rosenberg S (2010) Myeloid-derived suppressor cells: more mechanisms for inhibiting antitumor immunity. Cancer Immunol Immunother 59:1593-1600 (review)

3. Dieckmann D, Plottner H, Berchtold S, Berger T, Schuler G (2001) Ex vivo isolation and characterization of $\mathrm{CD} 4(+)$ $\mathrm{CD} 25(+) \mathrm{T}$ cells with regulatory properties from human blood. J Exp Med 193:1303-1310

4. Liyanage UK, Moore TT, Joo HG, Tanaka Y, Herrmann V, Doherty G, Drebin JA, Strasberg SM, Eberlein TJ, Goedegebuure PS, Linehan DC (2002) Prevalence of regulatory $T$ cells is increased in peripheral blood and tumor microenvironment of patients with pancreas or breast adenocarcinoma. J Immunol 169:2756-2761

5. Sakaguchi S (2000) Regulatory T cells: key controllers of immunologic self-tolerance. Cell 101:455-458 (review)

6. Seddiki N, Santner-Nanan B, Martinson J, Zaunders J, Sasson S, Landay A, Solomon M, Selby W, Alexander SI, Nanan R, Kelleher A, Fazekas de St Groth B (2006) Expression of interleukin (IL)-2 and IL-7 receptors discriminates between human regulatory and activated T cells. J Exp Med 203:16931700
7. Hiraoka N, Onozato K, Kosuge T, Hirohashi S (2006) Prevalence of FOXP3 + regulatory $\mathrm{T}$ cells increases during the progression of pancreatic ductal adenocarcinoma and its premalignant lesions. Clin Cancer Res 12:5423-5434

8. Schmielau J, Finn OJ (2001) Activated granulocytes and granulocyte-derived hydrogen peroxide are the underlying mechanism of suppression of t-cell function in advanced cancer patients. Cancer Res 61:4756-4760

9. Diaz-Montero CM, Salem ML, Nishimura MI, Garrett-Mayer E, Cole DJ, Montero AJ (2009) Increased circulating myeloidderived suppressor cells correlate with clinical cancer stage, metastatic tumor burden, and doxorubicin-cyclophosphamide chemotherapy. Cancer Immunol Immunother 58:49-59

10. Rodriguez PC, Zea AH, DeSalvo J, Culotta KS, Zabaleta J, Quiceno DG, Ochoa JB, Ochoa AC (2003) L-arginine consumption by macrophages modulates the expression of $\mathrm{CD} 3$ zeta chain in T lymphocytes. J Immunol 171:1232-1239

11. Rodriguez PC, Quiceno DG, Zabaleta J, Ortiz B, Zea AH, Piazuelo MB, Delgado A, Correa P, Brayer J, Sotomayor EM, Antonia S, Ochoa JB, Ochoa AC (2004) Arginase I production in the tumor microenvironment by mature myeloid cells inhibits $\mathrm{T}$-cell receptor expression and antigen-specific T-cell responses. Cancer Res 64:5839-5849

12. Zea AH, Rodriguez PC, Atkins MB, Hernandez C, Signoretti S, Zabaleta J, McDermott D, Quiceno D, Youmans A, O'Neill A, Mier J, Ochoa AC (2005) Arginase-producing myeloid suppressor cells in renal cell carcinoma patients: a mechanism of tumor evasion. Cancer Res 65:3044-3048

13. Hoechst B, Ormandy LA, Ballmaier M, Lehner F, Krüger C, Manns MP, Greten TF, Korangy F (2008) A new population of myeloid-derived suppressor cells in hepatocellular carcinoma patients induces CD4(+)CD25(+)Foxp3(+) T cells. Gastroenterology 135:234-243

14. Ko JS, Zea AH, Rini BI, Ireland JL, Elson P, Cohen P, Golshayan A, Rayman PA, Wood L, Garcia J, Dreicer R, Bukowski R, Finke JH (2009) Sunitinib mediates reversal of myeloid-derived suppressor cell accumulation in renal cell carcinoma patients. Clin Cancer Res 15:2148-2157

15. Bellone G, Turletti A, Artusio E, Mareschi K, Carbone A, Tibaudi D, Robecchi A, Emanuelli G, Rodeck U (1999) Tumorassociated transforming growth factor-beta and interleukin-10 contribute to a systemic Th2 immune phenotype in pancreatic carcinoma patients. Am J Pathol 155:537-547

16. Lechner MG, Liebertz DJ, Epstein AL (2010) Characterization of cytokine-induced myeloid-derived suppressor cells from normal human peripheral blood mononuclear cells. J Immunol $185: 2273-2284$ 
17. Bunt SK, Yang L, Sinha P, Clements VK, Leips J, OstrandRosenberg S (2007) Reduced inflammation in the tumor microenvironment delays the accumulation of myeloid-derived suppressor cells and limits tumor progression. Cancer Res 67: 10019-10026

18. Yurkovetsky ZR, Kirkwood JM, Edington HD, Marrangoni AM, Velikokhatnaya L, Winans MT, Gorelik E, Lokshin AE (2007) Multiplex analysis of serum cytokines in melanoma patients treated with interferon-alpha2b. Clin Cancer Res 13:2422-2428

19. Bellone G, Smirne C, Mauri FA, Tonel E, Carbone A, Buffolino A, Dughera L, Robecchi A, Pirisi M, Emanuelli G (2006) Cytokine expression profile in human pancreatic carcinoma cells and in surgical specimens: implications for survival. Cancer Immunol Immunother 55:684-698

20. Formentini A, Prokopchuk O, Sträter J, Kleeff J, Grochola LF, Leder G, Henne-Bruns D, Korc M, Kornmann M (2009) Interleukin-13 exerts autocrine growth-promoting effects on human pancreatic cancer, and its expression correlates with a propensity for lymph node metastases. Int J Colorectal Dis 24:57-67

21. Gallina G, Dolcetti L, Serafini P, De Santo C, Marigo I, Colombo MP, Basso G, Brombacher F, Borrello I, Zanovello P, Bicciato S, Bronte V (2006) Tumors induce a subset of inflammatory monocytes with immunosuppressive activity on CD8+ T cells. J Clin Invest 116:2777-2790
22. Mandruzzato S, Solito S, Falisi E, Francescato S, Chiarion-Sileni V, Mocellin S, Zanon A, Rossi CR, Nitti D, Bronte V, Zanovello P (2009) IL4Ralpha+ myeloid-derived suppressor cell expansion in cancer patients. J Immunol 182:6562-6568

23. Highfill SL, Rodriguez PC, Zhou Q, Goetz CA, Koehn BH, Veenstra R, Taylor PA, Panoskaltsis-Mortari A, Serody JS, Munn DH, Tolar J, Ochoa AC, Blazar BR (2010) Bone marrow myeloid-derived suppressor cells (MDSCs) inhibit graft-versus-host disease (GVHD) via an arginase-1-dependent mechanism that is up-regulated by interleukin-13. Blood 116:5738-5747

24. Rodriguez PC, Ernstoff MS, Hernandez C, Atkins M, Zabaleta J, Sierra R, Ochoa AC (2009) Arginase I-producing myeloidderived suppressor cells in renal cell carcinoma are a subpopulation of activated granulocytes. Cancer Res 69:1553-1560

25. Nagaraj S, Youn JI, Weber H, Iclozan C, Lu L, Cotter MJ, Meyer C, Becerra CR, Fishman M, Antonia S, Sporn MB, Liby KT, Rawal B, Lee JH, Gabrilovich DI (2010) Anti-inflammatory triterpenoid blocks immune suppressive function of MDSCs and improves immune response in cancer. Clin Cancer Res 16:1812-1823

26. Shimamura T, Fujisawa T, Husain SR, Joshi B, Puri RK (2010) Interleukin 13 mediates signal transduction through interleukin 13 receptor alpha2 in pancreatic ductal adenocarcinoma: role of IL-13 Pseudomonas exotoxin in pancreatic cancer therapy. Clin Cancer Res 16:577-586 